\title{
Cholinergic Basal Forebrain Structure Influences the Reconfiguration of White Matter Connections to Support Residual Memory in Mild Cognitive Impairment
}

\author{
Nicola J. Ray, ${ }^{1}$ CClaudia Metzler-Baddeley, ${ }^{3}$ Mizanur R. Khondoker, ${ }^{2}{ }^{\circledR}$ Michel J. Grothe, ${ }^{5}$ Stefan Teipel, ${ }^{4}$

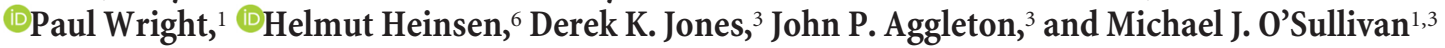 \\ Department of ${ }^{1}$ Basic and Clinical Neuroscience and ${ }^{2}$ Biostatistics, Institute of Psychiatry, Psychology and Neuroscience, King's College London, London \\ SE5 8AF, United Kingdom, ${ }^{3}$ Cardiff University Brain Research Imaging Centre, School of Psychology, and Neuroscience and Mental Health Research \\ Institute, Cardiff, CF10 3AT, United Kingdom, ${ }^{4}$ German Center for Neurodegenerative Diseases Rostock/Greifswald, D-18471 Rostock, Germany, \\ ${ }^{5}$ Department of Psychosomatic Medicine, University Medicine Rostock, D-18147 Rostock, Germany, and 'Laboratory of Morphological Brain Research, \\ Department of Psychiatry, Psychosomatic Medicine and Psychotherapy, University of Würzburg, D-97080 Würzburg, Germany
}

The fornix and hippocampus are critical to recollection in the healthy human brain. Fornix degeneration is a feature of aging and Alzheimer's disease. In the presence of fornix damage in mild cognitive impairment (MCI), a recognized prodrome of Alzheimer's disease, recall shows greater dependence on other tracts, notably the parahippocampal cingulum (PHC). The current aims were to determine whether this shift is adaptive and to probe its relationship to cholinergic signaling, which is also compromised in Alzheimer's disease. Twenty-five human participants with MCI and 20 matched healthy volunteers underwent diffusion MRI, behavioral assessment, and volumetric measurement of the basal forebrain. In a regression model for recall, there was a significant group $\times$ fornix interaction, indicating that the association between recall and fornix structure was weaker in patients. The opposite trend was present for the left PHC. To further investigate this pattern, two regression models were generated to account for recall performance: one based on fornix microstructure and the other on both fornix and left PHC. The realignment to PHC was positively correlated with free recall but not non-memory measures, implying a reconfiguration that is beneficial to residual memory. There was a positive relationship between realignment to $\mathrm{PHC}$ and basal forebrain gray matter volume despite this region demonstrating atrophy at a group level, i.e., the cognitive realignment to left PHC was most apparent when cholinergic areas were relatively spared. Therefore, cholinergic systems appear to enable adaptation to injury even as they degenerate, which has implications for functional restoration.

Key words: cholinergic system; diffusion; episodic memory; fornix; mild cognitive impairment; white matter

\section{Introduction}

Recollective memory is central to the human experience but is devastated by common diseases of old age, notably Alzheimer's disease. The fornix, which contains axons that connect the hippocampal formation with the mammillary bodies, thalamus, and

Received Aug. 29, 2014; revised Nov. 6, 2014; accepted Nov. 12, 2014.

Author contributions: N.J.R., S.T., H.H., D.K.J., J.P.A., and M.J.O. designed research; N.J.R., C.M.-B., M.R.K., M.J.G., S.T., D.K.J., J.P.A., and M.J.O. performed research; N.J.R., C.M.-B., M.R.K., M.J.G., S.T., P.W., H.H., D.K.J., J.P.A., and M.J.O. analyzed data; N.J.R., C.M.-B., M.R.K., M.J.G., S.T., P.W., H.H., D.K.J., J.P.A., and M.J.O. wrote the paper.

This project was funded by Medical Research Council Grants G0701912 and MR/K022113/1. M.R.K. receives salary support from the National Institute for Health Research (NIHR) (Mental Health Biomedical Research Centre) at South London, Maudsley National Health Service Foundation Trust, and King's College London. M.J.O. receives support from the NIHR Biomedical Research Unit for Dementia. C.M.-B. and D.K.J. are supported by the Wellcome Trust.

The authors declare no competing financial interests.

This article is freely available online through the J Neurosci Author Open Choice option.

Correspondence should be addressed to Michael O'Sullivan, Department of Basic and Clinical Neuroscience, Institute of Psychiatry, Psychology and Neuroscience, King's College London, London SE5 8AF, UK. E-mail: mike.osullivan@kcl.ac.uk.

D0I:10.1523/JNEUROSCI.3617-14.2015

Copyright $\odot 2015$ Ray et al.

This is an Open Access article distributed under the terms of the Creative Commons Attribution License (http://creativecommons.org/licenses/by/3.0), which permits unrestricted use, distribution and reproduction in any medium provided that the original work is properly attributed. prefrontal cortex (Poletti and Creswell, 1977; Aggleton et al., 1987; Saunders and Aggleton, 2007), plays a key role in recollection (Gaffan and Gaffan, 1991; Aggleton and Brown, 2006). Damage from tumor (McMackin et al., 1995; Aggleton et al., 2000, Tsivilis et al., 2008) or trauma (D'Esposito et al., 1995) impairs recall with a relative sparing of familiarity-based memory (Vann et al., 2009). Variations in fornix microstructure, evaluated by diffusion MRI, are also associated with recollection in young (Rudebeck et al., 2009) and older (Metzler-Baddeley et al., 2011) adults. Microstructural alterations of the fornix are evident in Alzheimer's disease and at an earlier stage of pathological decline represented by mild cognitive impairment (MCI), which is often a precursor of Alzheimer's disease (Sexton et al., 2010; Metzler-Baddeley et al., 2012a).

The magnitude of fornix transection effects in animals shows dependence on other brain systems. For example, combined fornix and cholinergic system lesions in rhesus monkeys not only produce memory impairment but a quantitative deficit that exceeds the sum of the individual lesions (Browning et al., 2010). In primates, cholinergic inputs to the hippocampus arise from basal forebrain nuclei, primarily from the medial septum and vertical 
limb of the diagonal band of Broca, which join the fornix, whereas those to the temporal cortex originate from nucleus basalis of Meynert (NBM) and take a direct, non-fornical route (Kitt et al., 1987; Koliatsos et al., 1988; Mesulam, 1995). Loss of cholinergic neurons in the basal forebrain is also a feature of Alzheimer's disease that is manifest in non-invasive measurements of gray matter volume in Alzheimer's disease and MCI (Grothe et al., 2012, 2013).

We have shown recently that fornix abnormalities in MCI coincide with a greater dependence of recall on other temporal association tracts, such as the parahippocampal cingulum (PHC; Metzler-Baddeley et al., 2012a). The present study determined how such changes in structure-function relationships might relate to the status of the cholinergic basal forebrain, which is also affected in MCI. If the weakening association between fornix structure and recall were simply attributable to involvement of the fornix in diffuse neurodegeneration, one might expect it to go hand-in-hand with worsening memory performance and gray matter atrophy (including loss of the basal forebrain). Alternatively, if the change in pattern of associations is adaptive and reflects useful reorganization of function, the opposite association with residual memory function might be found. More specifically, if the cholinergic system is involved in neural adaptation, as has been suggested (Croxson et al., 2012), this realignment in association from fornix to PHC might correlate positively with spared basal forebrain tissue. To test these competing predictions, we combined diffusion MRI and tractography with a volumetric method to evaluate cholinergic nuclei in the basal forebrain that has been validated against histological landmarks postmortem (Teipel et al., 2005).

\section{Materials and Methods}

\section{Participants}

Twenty-five patients of either sex (11 females) with MCI were recruited from the Cardiff Memory Clinic. The diagnosis was based on established current criteria (Albert et al., 2011). Objective memory impairment was confirmed by a score of 1.5 SDs below age-matched controls on either the verbal memory subscore of the Addenbrooke's Cognitive Examination (Mioshi et al., 2006) or the visual memory test from the Repeatable Battery for the Assessment of Neurological Status (Randolph et al., 1998). All patients had a Mini-Mental State Examination score $>24$ (mean, $26 \pm 1.7$ ) and a Clinical Dementia Rating of 0.5 (Morris, 1993). Exclusion criteria were as follows: (1) previous moderate to severe head injury; (2) previous or current alcohol or drug abuse (as defined by Diagnostic and Statistical Manual of Mental Disorders IV, Text Revision); (3) previous large-artery or disabling stroke or cerebral hemorrhage; (4) known peripheral, cervical, or coronary artery disease; (5) structural heart disease or heart failure; and (6) contraindications to MRI. In addition, no patient met diagnostic criteria or had characteristic cognitive or behavioral features to suggest other degenerative disorders (e.g., dementia with Lewy bodies or frontotemporal lobar degenerations). Consecutive patients, who were eligible and willing to take part, were recruited and assessed by a single neurologist (M.J.O.).

The 20 healthy control participants were a subgroup of a sample of 46 individuals between the ages of 53 and 93 years, recruited for an aging study (Metzler-Baddeley et al., 2011). The subgroup was selected to provide optimal matching of demographic variables, but selection was performed blinded to memory scores and imaging data. Those over the age of 65 years (the MCI group were all over 65 years) and with a verbal IQ not exceeding 2 SDs above the average patient IQ in the National Adult Reading Test-Revised (Nelson and Willison, 1991) were included ( $n=$ 20; see Table 1). Subgroup selection was based entirely on demographic variables and verbal intelligence. Exclusion criteria for the healthy participants were identical to those for the patient group with the addition of no significant previous symptoms related to memory.
Table 1. Group demographics, single-tract comparisons, and cognitive scores

\begin{tabular}{lccl}
\hline & Healthy older adults & $\mathrm{MCl}$ & $p$ (unpaired $t$ test) \\
\hline Age (years) & $74 \pm 7$ & $77 \pm 8$ & $\mathrm{NS}$ \\
Education (years) & $16 \pm 3$ & $14 \pm 4$ & $\mathrm{NS}$ \\
NART IQ & $115 \pm 28$ & $115 \pm 11$ & $\mathrm{NS}$ \\
Delayed free recall & $11 \pm 3$ & $4 \pm 4$ & $<0.001$ \\
Immediate free recall & $29 \pm 8$ & $13 \pm 10$ & $<0.001$ \\
DP visual recognition & & $12.6 \pm 4.5$ & $\mathrm{NA}$ \\
Fornix $f$ & $0.62 \pm 0.07$ & $0.55 \pm 0.09$ & 0.003 \\
Left PHC $f$ & $0.90 \pm 0.02$ & $0.90 \pm 0.02$ & $\mathrm{NS}$ \\
Left uncinate $f$ & $0.89 \pm 0.02$ & $0.87 \pm 0.05$ & $\mathrm{NS}$ \\
Digit symbol & $56.4 \pm 18.6$ & $35.6 \pm 12.3$ & $<0.001$ \\
Stroop suppression & $96.1 \pm 15.7$ & $57.4 \pm 28.2$ & $<0.001$ \\
\hline
\end{tabular}

Scores are shown as mean \pm SD. $p$ values for between-group comparisons with $t$ test are presented in the last column. DP, Doors and People; NA, not applicable; NART, National Adult Reading Test.

The study protocol was reviewed and approved by the South East Wales National Health Service Research Ethics Committee. All participants provided informed, written consent.

\section{MRI acquisition}

Diffusion MRI scans were acquired on a 3 T GE HDx MRI (GE Healthcare) using an eight-channel receive-only head radiofrequency coil with a twice-refocused spin-echo echo-planar imaging sequence providing whole-brain coverage (60 slices, $2.4 \mathrm{~mm}$ thickness, $23 \mathrm{~cm}$ field of view; $96 \times 96$ acquisition matrix). Acquisition was peripherally gated to the cardiac cycle. Echo delay time was $87 \mathrm{~ms}$, and parallel imaging (ASSET factor 2) was used. The $b$ value was $1200 \mathrm{~s} / \mathrm{mm}^{2}$. Data were acquired with diffusion encoded along 30 isotropically distributed orientations and three non-diffusion-weighted scans (Jones et al., 1999). Acquisition time was $\sim 13 \mathrm{~min}$. Images were corrected for distortions, introduced by the diffusion-weighted gradients, and for subject motion with appropriate reorienting of the encoding vectors (Leemans and Jones, 2009).

T1-weighted structural MRI data were acquired using a 3D fast spoiled gradient recalled echo sequence, acquired with a matrix of $256 \times 256 \times$ 176 and field of view of $256 \times 256 \times 176$, resulting in isotropic $1 \mathrm{~mm}$ resolution. The parameters were as follows: repetition time, $7.9 \mathrm{~ms}$; echo time, $3.0 \mathrm{~ms}$; inversion time $450 \mathrm{~ms}$; and flip angle, $20^{\circ}$.

\section{Diffusion tractography and tract-specific indices}

Tractography was performed using ExploreDTI (www.exploreDTI. com). The diffusion tensor model was used to reconstruct the uncinate fasciculus and the PHC. The tensor model is less suitable for the fornix because of its close proximity to other orthogonal white matter tracts (e.g., anterior commissure). Therefore, the fornix was reconstructed using deterministic tracking based on constrained spherical deconvolution (Tournier et al., 2007, 2008; Jeurissen et al., 2011), as developed in a previous methodological study (Metzler-Baddeley et al., 2012b) and used in previous studies (Metzler-Baddeley et al., 2011, 2012a). The deterministic tracking algorithm estimated the principal diffusion orientation at each seed point and propagated in $0.5 \mathrm{~mm}$ steps along this direction. The fiber orientations were then estimated at the new location, and the tracking moved an additional $0.5 \mathrm{~mm}$ along the direction that subtended the smallest angle to the current trajectory. A trajectory was traced through the data until the scaled height of the fiber orientation density function peak fell below 0.1 (or the fractional anisotropy fell below 0.15 ) or the direction of the pathway changed through an angle $>60^{\circ}$.

Initial whole-brain tractography was performed using every voxel as a seed point. Three-dimensional reconstructions of the fornix, PHC (Fig. 1) and uncinate were then extracted by applying multiple waypoint regions of interest and Boolean logical operations (for example, fibers that traversed regions 1 and 2 but not region 3). Regions of interest were manually drawn in native space on color-coded fiber orientation maps by a single blinded operator (C.M.-B.), using established landmark techniques used and described in detail in previous published work (MetzlerBaddeley et al., 2011, 2012a).

Contamination from CSF is a particular problem for tract-based diffusion measurements, especially those derived from the fornix (Metzler- 


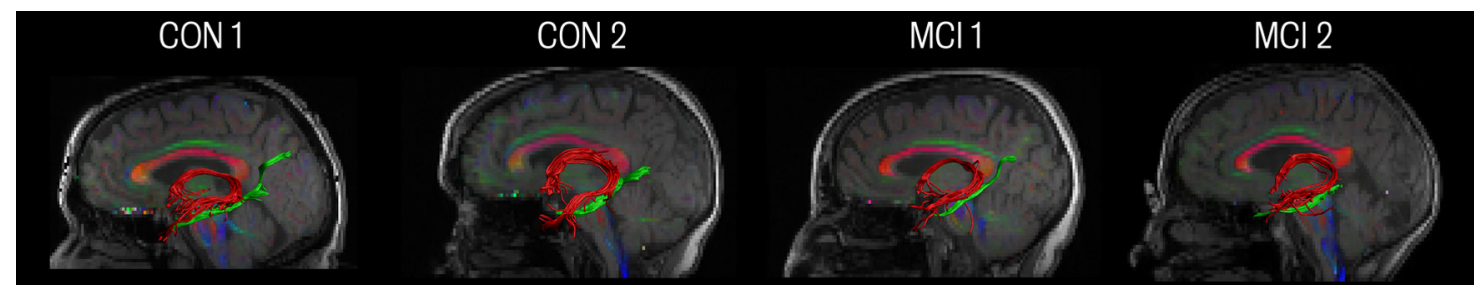

Figure 1. Reconstructions of the fornix and left PHC. Example reconstructions are shown in two patients with MCI (MCI1, MCI2) and two controls (CON1, CON2). The fornix is shown in red and the left PHC in green. Tract reconstructions are shown overlaid on individual sagittal sections of a fusion image of the T1-weighted image and the color-coded fractional anisotropy image (red, left-right fiber direction; green, anterior-posterior; blue, inferior-superior).

Table 2. Multiple linear regression model for delayed free recall

\begin{tabular}{lrrc}
\hline & Standardized coefficient $(\beta)$ & \multicolumn{1}{l}{$t$} & $p$ \\
\hline Constant & & 11.48 & $<0.001$ \\
Group & -0.65 & -5.78 & $<0.001$ \\
Fornix $f$ & 0.45 & 2.49 & 0.018 \\
Left PHC $f$ & 0.15 & 0.86 & 0.40 \\
Group $\times$ fornix finteraction & -0.38 & -2.17 & 0.037 \\
Group $\times$ left PHC finteraction & 0.11 & 0.57 & 0.57 \\
\hline
\end{tabular}

Baddeley et al., 2012b). Therefore, before extracting tract-specific microstructural measures, the free water elimination approach was used to correct for CSF contamination (Pasternak et al., 2009; Berlot et al., 2014). Mean, axial, radial diffusivities and fractional anisotropy measures were then extracted as an average across all waypoints of each tract. Free water elimination involves fitting a bi-tensor model to diffusion data in each voxel: one that models the contribution of free water and a separate tensor that models tissue (gray or white matter). The model also fits the term $f$, or tissue volume fraction, which represents the volume fraction of tissue within the voxel (Pasternak et al., 2009).

\section{Choice and evaluation of tract metrics}

In the previous study, $f$ was most sensitive to MCI-related changes in fornix microstructure compared with more commonly used measures, such as fractional anisotropy and mean diffusivity (Metzler-Baddeley et al., 2012a). Therefore, $f$ was chosen as the optimal measure to represent tract microstructure.

To assess intra-rater reproducibility, pilot studies were performed in a subset of participants sampled from both groups. Reproducibility was high for all tracts and measures: ( 1$)$ uncinate $(n=12$, left and right in six subjects) intraclass correlation coefficient $>0.99$, coefficient of variation $<1 \%$ for all diffusion metrics; (2) PHC ( $n=12$, left and right in six subjects) intraclass correlation coefficient $>0.99$, coefficient of variation $<1 \%$ for all diffusion metrics; and (3) fornix $(n=5)$ intraclass correlation of 0.85 , coefficient of variation of $5.4 \%$.

\section{Volumetric assessment of the basal forebrain}

T1-weighted high-resolution anatomical images were processed using Statistical Parametric Mapping (SPM; version 8; Wellcome Trust Center for Neuroimaging) and the VBM8 toolbox (http://dbm.neuro.uni-jena. $\mathrm{de} / \mathrm{vbm})$. The images were first segmented into gray matter, white matter, and CSF using the VBM8 toolbox. The gray and white matter images for each group were then high dimensionally registered to each other using diffeomorphic anatomical registration through exponentiated lie algebra (DARTEL; Ashburner, 2007). This technique created groupspecific templates for patient and healthy control groups and the pooled sample of both groups. These templates were then transformed to Montreal Neurological Institute (MNI) standard space, and the transformation parameters were combined with the individual flow-fields from the DARTEL procedure and used for registering the gray matter images into MNI space. Voxel values were modulated to preserve the total amounts of gray and white matter volume throughout warping procedures. The gray matter images were then resampled to an isotropic voxel size of 1 $\mathrm{mm}$ and smoothed with a Gaussian smoothing kernel of $4 \mathrm{~mm}$ full-width at half-maximum. For a separate whole-brain analysis, a smoothing kernel of $8 \mathrm{~mm}$ was applied.

To measure gray matter volume specifically within the basal forebrain cholinergic nuclei, a map of these nuclei that has been histologically validated against postmortem anatomy was used (Teipel et al., 2005; Grothe et al., 2012, 2013). The validated map was derived in MNI standard space so it could be directly applied to template-registered individual subject scans. The basal forebrain cholinergic system map was used as a mask: voxel-by-voxel gray matter volume values within this mask were compared across groups and entered in regression models.

\section{Cognitive assessment}

Neuropsychological assessment was performed over two $1.5 \mathrm{~h}$ testing sessions. Premorbid verbal intelligence was estimated with the National Adult Reading Test, Revised. Episodic memory was assessed with instruments that index different aspects of memory processing, including the Free and Cued Selective Reminding Test (FCSRT; Grober et al., 1997) and the Doors and People recognition memory test (Baddeley et al., 1994). Three measures of verbal recall were included: immediate and delayed free recall on the FCSRT and verbal recall from the Doors and People test. Measures of free recall are strongly associated with fornix structure in healthy volunteers and were not strongly affected by ceiling or floor effects in the previous MCI study (Metzler-Baddeley et al., 2011, 2012a). Tests of recognition memory are subject to ceiling effects in healthy volunteers but are sensitive to residual memory function in MCI. Therefore, verbal and visual recognition on the Doors and People task were added as measures of recognition memory for analyses in the MCI group only. Executive functions were also assessed with a range of tasks, including the Stroop (Trenerry et al., 1989), Tower of London (Delis et al., 2001), and the Digit Symbol Substitution (Wechsler, 1999) tasks. Stroop suppression (correct color words read when printed in an incongruent-colored ink) and Digit Symbol Substitution total score were selected as control measures: non-memory tasks that also differ between patients and controls (Metzler-Baddeley et al., 2011).

\section{Multiple linear regression}

To evaluate shifts in association among white matter tracts, a single regression model was constructed for all participants with delayed verbal free recall as the dependent variable. Selected tract measures were included (see below). In addition, group (healthy older adult or MCI) was included as an independent variable (coded as control $=0$ and MCI $=1$ ).

Variable selection. Tracts were selected for the model on the basis of a significant univariate association with verbal free recall in either healthy older adult or MCI group. On this basis, fornix $f$ and left PHC $f$ were included (Metzler-Baddeley et al., 2012a). All variables selected in this way were entered simultaneously, in a single step, into the regression model.

Evaluation of shifts in association in MCI. To formally evaluate shifts in association between control and MCI groups, group $\times$ tract interaction terms were included. A positive value for the coefficient of an interaction would indicate that the association was stronger in the patient group. To explore interactions in more detail, we quantified the change in goodness-of-fit for two simple regression models. The first model used group and fornix microstructure to predict performance. In the second model, left PHC $f$ was an additional independent variable. A better fit would be expected in a model with an additional predictor variable. 
$\mathrm{MCl}$

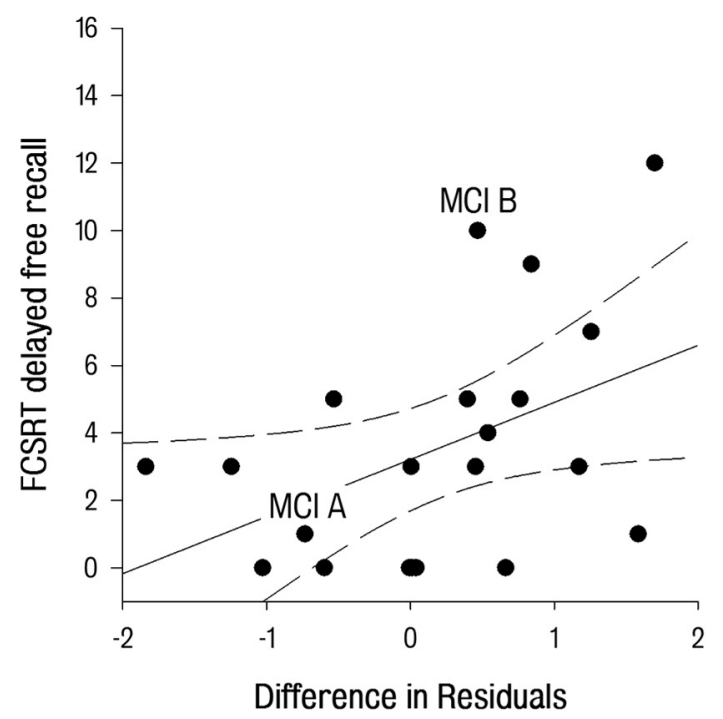

MCI

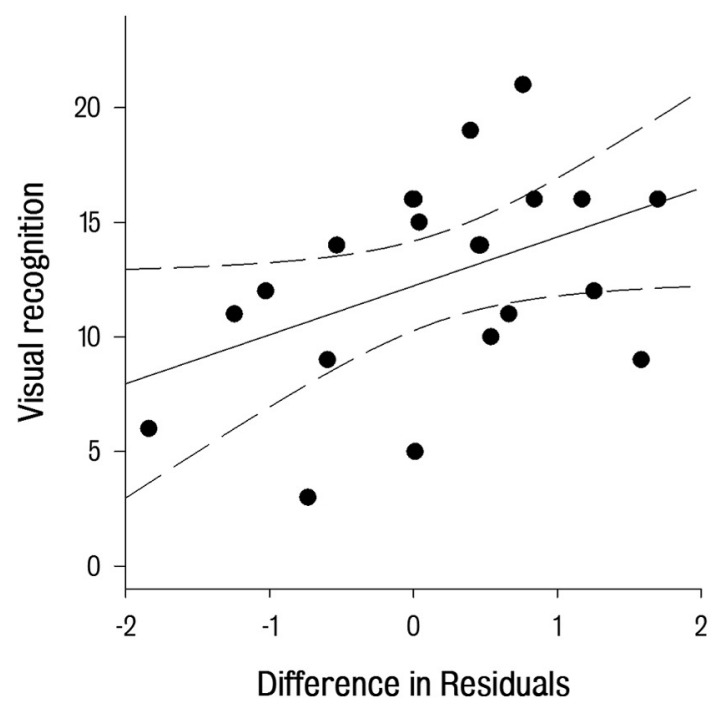

\section{Controls}

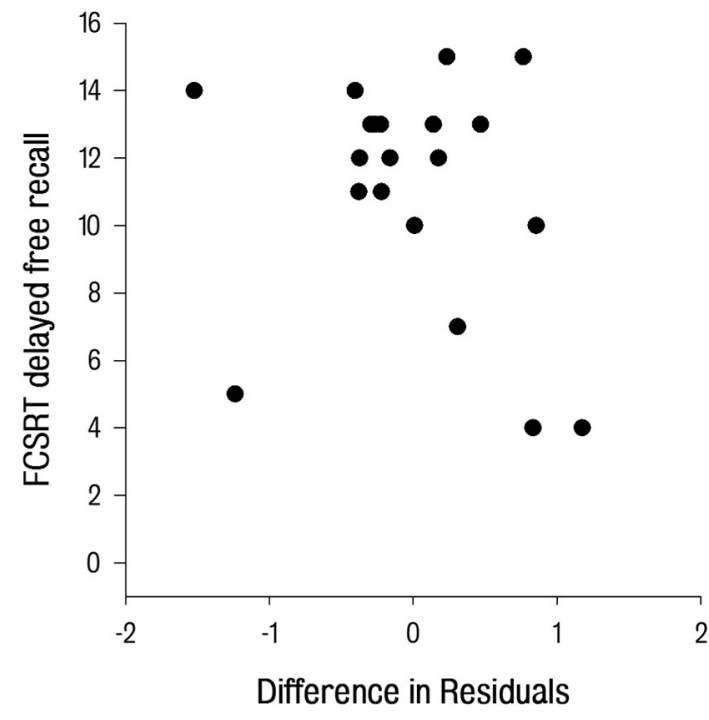

Controls

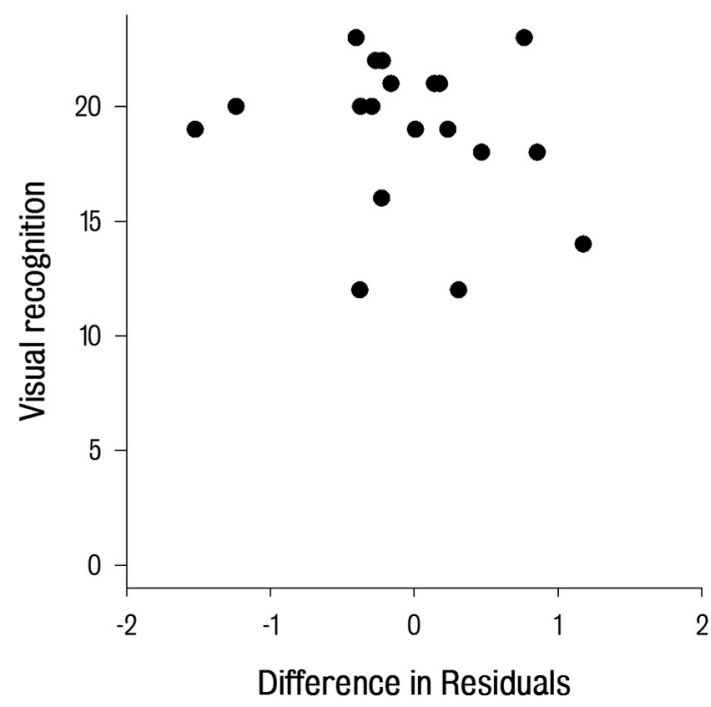

Figure 2. Cognitive realignment and episodic memory performance. DR — a measure of the increase in relative importance of the left PHC — plotted against delayed free recall from the FCSRT (top) and visual recognition from the Doors and People test (bottom). In MCl patients, DR correlated with both free recall (top left; $r=0.45, p<0.05$ ) and visual recognition (bottom left; $r=0.44$, $p<0.05$ ). In controls, there was no evidence of correlation (top right and bottom right). Solid lines show linear regression fit, and dashed lines show $95 \%$ confidence interval of regression. In the top left, two individuals with MCI (MCI A, MCI B) are labeled as examples for additional exploration of interactions between structure and performance in Figure 4.

Table 3. Correlations between DR, age, and memory

\begin{tabular}{llll}
\hline & $\begin{array}{l}\text { Healthy older } \\
\text { adults }\end{array}$ & $\mathrm{MCl}$ & $\begin{array}{l}p \text {, difference in } \\
\text { correlations }\end{array}$ \\
\hline Age (years) & $0.55^{* *}$ & 0.02 & 0.08 \\
$\begin{array}{l}\text { Memory } \\
\quad \text { FCSRT immediate free recall }\end{array}$ & $-0.46^{*}$ & $0.50^{* *}$ & 0.002 \\
$\quad$ FCSRT delayed free recall & -0.26 & $0.45^{*}$ & 0.01 \\
$\quad$ Doors and People verbal recall & -0.17 & $0.39^{*}$ & 0.04 \\
$\quad$ Doors and People verbal recognition & -0.10 & 0.10 & 0.27 \\
$\quad$ Doors and People visual recognition & -0.19 & $0.44^{*}$ & 0.05 \\
Executive function & & & \\
$\quad \begin{array}{l}\text { Digit symbol } \\
\text { Stroop suppression }\end{array}$ & -0.14 & 0.10 & 0.24 \\
\hline
\end{tabular}

${ }^{*} p<0.05$ uncorrected; ${ }^{* *} p<0.05$ after Bonferroni's correction. DR was calculated from two regression models, one with only fornix and the other with both fornix and left PHC as predictors of free recall performance. Higher values of DR indicate greater explanatory power of the model that included the left PHC, indicating a realignment in association for recall to non-fornical tracts.
However, the magnitude of this improvement provides an index of the additional explanatory power of a model that combines both fornix and left PHC rather than fornix alone. For each individual, the unsigned differences between the predicted and actual values obtained from each model (residuals) served as a measure of the ability of that model to account for that individual's performance. The unsigned residuals obtained from the second model (fornix and left PHC) were subtracted from those obtained from the first (fornix only) model. A larger value indicated a greater advantage for the model based on both tracts in accounting for memory performance in that individual. This index will be referred to as DR (difference in residuals). For comparison, DR values were also computed for right $\mathrm{PHC}$ and left and right uncinate fasciculi.

\section{Statistical analysis of imaging and cognitive associations}

Reconstruction of the PHC was not possible in one hemisphere in four patients. One additional patient had impaired vision and did not complete the visual recognition memory tasks. Therefore, cognitive data and 

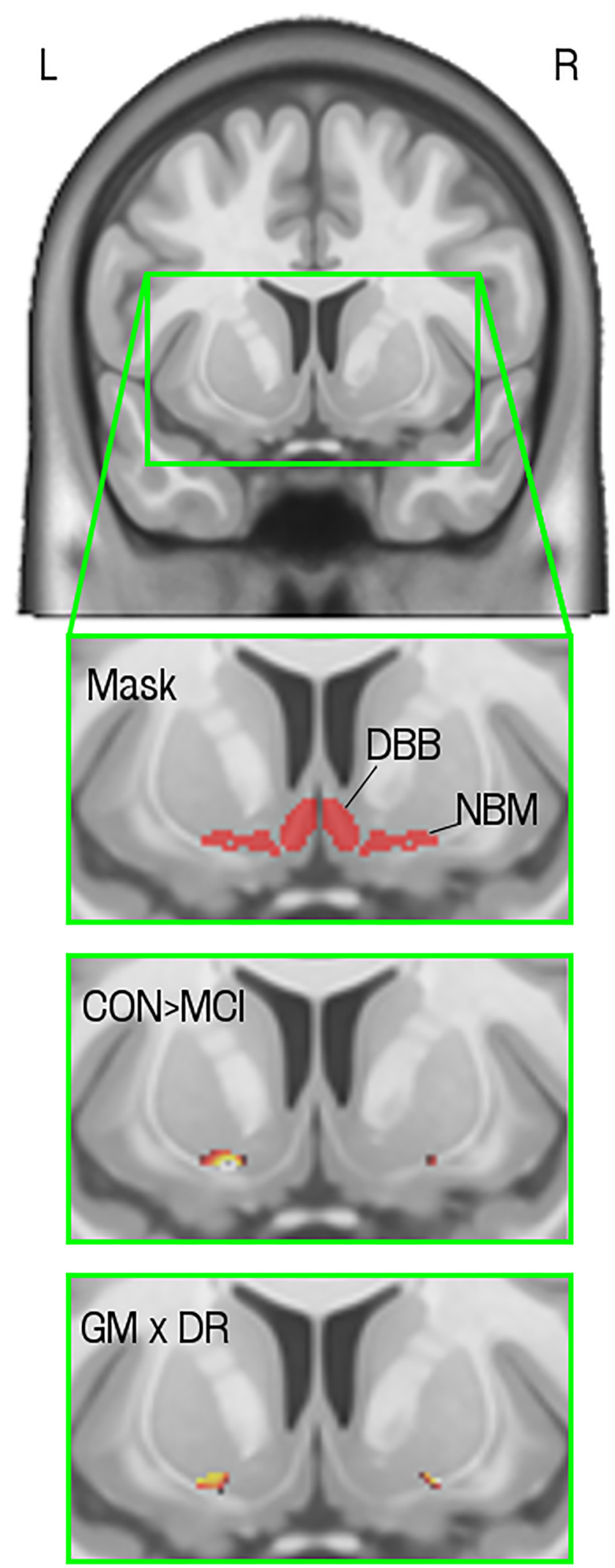

Figure 3. Volumetric evaluation of the basal forebrain cholinergic system. Top, Single coronal slice from the Montreal Neurological Institute MNI152 atlas brain. A region including the basal forebrain is magnified to show the mask and results (green square; $L$, left; $R$, right). Mask, A cross-section of the three-dimensional cholinergic basal forebrain mask: voxels filled in red are part of the mask. Approximate locations of the diagonal band of Broca (DBB) and NBM are indicated. This slice shows a small part of the NBM, referred to as the anterolateral subdivision fornix measurements were available for 24 patients, and complete data for cognitive measures, fornix, PHC, and uncinate fasciculi were available for 21 patients.

To test the behavioral relevance of DR, Pearson's correlation coefficients with memory scores were computed in each group. Based on an a priori prediction that non-fornical tracts are recruited as a compensatory mechanism, one-tailed $p$ values were computed for the positive relationships between memory and DR. In addition, a Bonferroni's correction was applied on the basis of inclusion of two recognition and three recall measures (with significance equivalent to an unadjusted threshold of $p<$ $0.01)$. Differences in correlation coefficients between groups were tested using Fisher's $r$-to- $z$ transformation, with $p$ values derived from the resultant $z$ statistic. To assess associations with cholinergic basal forebrain volume, all individuals were included in a regression model in SPM. Positive and negative associations between DR and gray matter volume, controlling for age, group, and total intracranial volume, were tested within the basal forebrain mask ( $p<0.05$ after correction for multiple comparisons via the familywise error approach (Nichols and Hayasaka, 2003).

Testing specificity of association: control comparisons

For associations with DR, specificity was assessed at three levels: (1) across hemispheres (left vs right for lateralized tracts); (2) across nonfornical tracts (PHC vs uncinate); and (3) across cognitive domains (memory vs executive scores). To test anatomical specificity of associations with cholinergic basal forebrain gray matter, regression was also performed with gray matter volume across the whole brain. The resultant maps of association were viewed at a liberal statistical threshold $(p<0.1$ uncorrected) to display any trends with a strength of association similar to that found within the basal forebrain, regardless of whether such regions reached whole-brain significance.

\section{Results}

The healthy older adults and MCI patients were of similar age, with matched National Adult Reading Test-IQ scores and levels of education (Table 1). Performance on the selected measures of episodic memory and executive function differed between groups. As expected based on previous analyses (MetzlerBaddeley et al., 2012a), significant differences in $f$ between the groups were restricted to the fornix $(t=3.34, p=0.001)$, and there was a significant main effect of group and fornix $f$ in the regression models for recall (Table 2).

\section{Shift to non-fornical tracts and behavioral performance}

There was a group $\times$ fornix interaction with a negative coefficient, indicating that the association between recall and fornix structure was significantly weaker in the patient group. The regression coefficient for the group $\times$ left $\mathrm{PHC}$ interaction term was positive, indicating that left $\mathrm{PHC}$ was more strongly associated with recall in MCI, although it was a nonsignificant interaction (Table 2).

To assess the effect of this shift on individual scores, individual measures of DR were correlated with behavioral performance. In the patient group, DR was positively associated with verbal free recall (Fig. 2). In contrast, DRs calculated for the right PHC or left

(Ch4al), that continues into the nucleus subputaminalis (described, to date, only in humans). The main part of the NBM extends posteriorly from this slice. CON $>$ MCI, Voxelwise two-sample $t$ test showing voxels with reduced gray matter volume in $\mathrm{MCl}$ patients compared with controls ( $p<0.05$ with familywise error correction). $G M \times D R$, Voxelwise regression of gray matter volume against DR showed that higher gray matter volume in the cholinergic basal forebrain predicted greater shift in association between tract microstructure and recall from fornix to the left PHC (voxel-level threshold, $p<0.001$ uncorrected). The region of association overlaps with the region of atrophy in $\mathrm{MCl}$ and is larger on the left, consistent with a change in pattern of associations toward left PHC in MCI. 

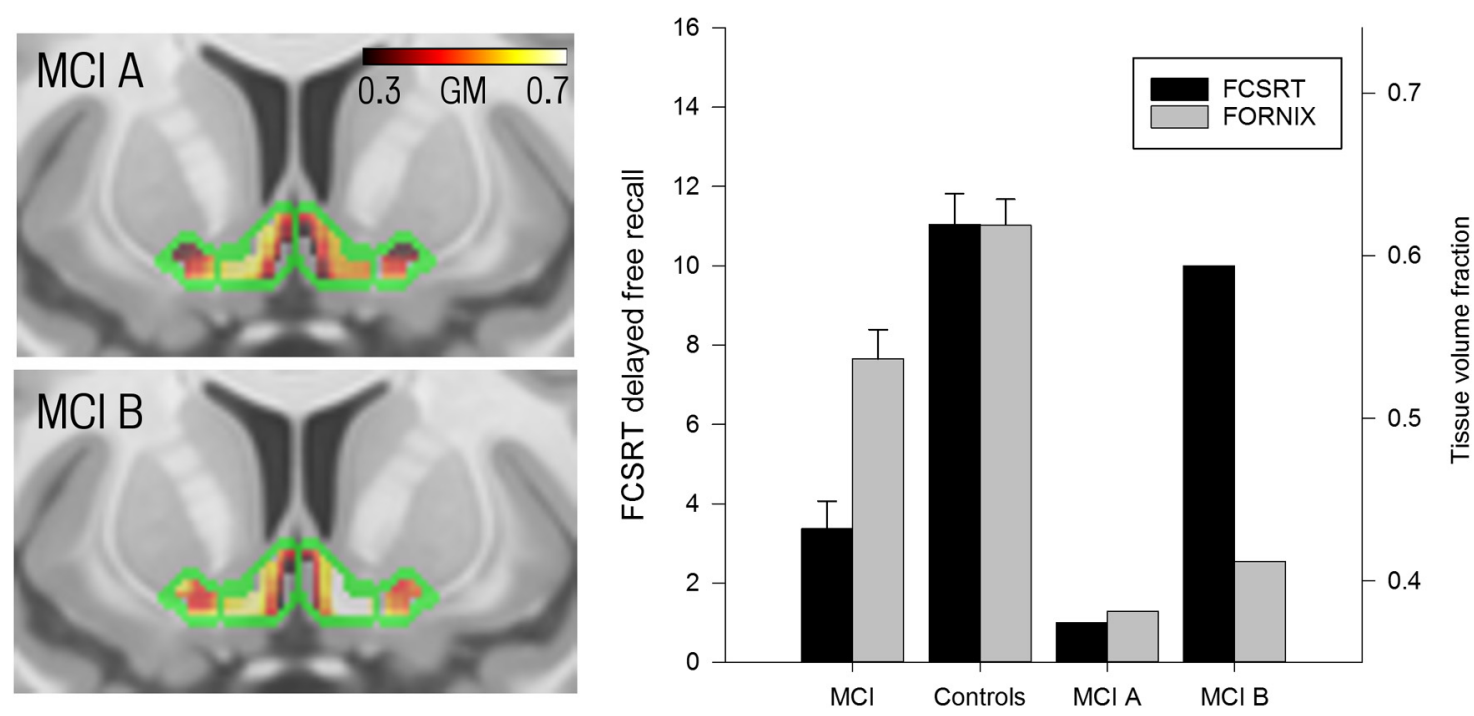

Figure 4. Interaction between cholinergic basal forebrain integrity and fornix microstructure in recall performance. Left, Gray matter integrity within the cholinergic basal forebrain mask in two patients with low and high recall scores (MCI A and MCI B, respectively; see Fig. 2). Green, Outline of the cholinergic basal forebrain mask. Red/yellow, Gray matter volume, as illustrated on color bar. Right, FCSRT delayed free recall scores (black) and fornix $f($ gray) for the MCl patient and control groups. The left part of bar chart shows group averages, labeled MCl and Controls, and the right part shows the two individual patients, MCI A and MCI B. Fornix $f$ and delayed free recall are both reduced in patients with $\mathrm{MCl}$ relative to controls. Patients $\mathrm{MCl} A$ and $M C I B$ both have fornix volume fractions that are below the mean for the MCI group generally. However, $\mathrm{MCI} B$ has preserved gray matter volume in the cholinergic basal forebrain as illustrated by the white/yellow colors in this region on the bottom left. This preservation coincides with a delayed free recall performance near the mean for the control group. In contrast, $\mathrm{MCl}$ A, who has both fornix compromise and atrophy in the cholinergic basal forebrain (red/black shading, top left), has marked impairment of delayed free recall.

and right uncinate fasciculi were not associated with performance on any measure. Furthermore, the correlation with DR of left PHC was specific for memory performance: no correlations were found with executive measures (Table 3).

\section{Volume of the cholinergic basal forebrain, MCI, and cognition}

A significant decrease in gray matter volume of the cholinergic basal forebrain was found in patients $(t=3.68, p<0.05$, corrected with familywise error; Fig. 3), with the most significant change seen in a region corresponding to the NBM. In a wholegroup analysis, there was a significant positive correlation between DR and gray matter volume in the cholinergic basal forebrain $(t=3.81, p<0.05$ corrected with familywise error for multiple comparisons) in a region that overlapped spatially with the presence of atrophy (Fig. 3). A voxel-based analysis extended to the whole brain revealed no other regions with a trend for association between gray matter volume and DR.

\section{Discussion}

Two key findings emerge from this study. First, the relative importance of fornix and left $\mathrm{PHC}$ as predictors of memory performance differed between patients with MCI and healthy older adults. This "shift" away from the damaged fornix was associated positively with performance. This implies a behaviorally relevant and useful cognitive reconfiguration of memory processes in response to pathology. The second, and more surprising, finding was the positive relationship between this cognitive shift and the volume of gray matter in the cholinergic nuclei of the basal forebrain, despite the fact that this region demonstrates atrophy in MCI (Fig. 3). The more standard account would be that both basal forebrain atrophy and the shift in memory associations to non-fornical pathways are features of a diffuse pathological process. This would predict the opposite result to that found, namely an increasing shift away from the damaged fornix associated with declining basal forebrain volume.
An explanation for the positive relationship with basal forebrain volume is offered by an order effect observed in lesion studies in the rhesus macaque. Fornix transection, when made after inferotemporal cholinergic depletion, produced a more severe deficit than when the order was reversed (Croxson et al., 2012), suggesting that acetylcholine has an early but lasting effect on ameliorating the consequences of white matter injury. Although such order effects cannot be tested directly in humans, the current results imply that they are present and influence performance. Thus, those individuals with established fornix damage but presumed relative preservation of the cholinergic system display greater reconfiguration of memory processing (large shift and DR) and performance near that of controls (Fig. 4), analogous to the effect of an intact cholinergic system in ameliorating the consequences of fornix transection in monkeys.

To measure gray matter volume in the basal forebrain, we relied on a map of the region produced from histological sections of a postmortem brain normalized into standard space (Teipel et al., 2005). Previous research using this map has revealed accelerated degeneration of the basal forebrain with age, which is exacerbated in MCI and Alzheimer's disease (Grothe et al., 2012, 2013). The cholinergic basal forebrain has been divided into four groups of cholinergic cells, designated Ch1-Ch4. Cell groups Ch1 (the medial septum) and Ch2 (vertical limb of the diagonal band) provide substantial projections to the hippocampus (Mesulam et al., 1983). Cell group Ch4, which corresponds to the NBM, projects to widespread areas of cortex (Mesulam et al., 1983). Although age-related atrophy appears to occur in the entire basal forebrain, disease-related changes are restricted primarily to the NBM (Grothe et al., 2012). The NBM, through its wide cortical projections (Mesulam et al., 1983), has been described as playing a role in a variety of cognitive processes, including memory and visual attention (Muir et al., 1993; Easton et al., 2012). In the present study, reduced gray matter volume was found in the region of the NBM in patients. Furthermore, the positive relation- 
ship with the shift to non-fornical tracts was localized to this region (Fig. 3).

Animal models of amnesia suggest that the most severe impairment occurs when damage to the hippocampus-fornix is accompanied by disconnection of the temporal cortex from its cholinergic inputs (Easton et al., 2012). Combined lesions in rhesus monkeys produce a quantitative deficit that exceeds the sum of effects from individual lesions (Browning et al., 2010). The corollary in humans, it has been argued (Horel, 1978; Gaffan, 2002), is the dense amnesia seen after bilateral medial temporal lobe resections (for example, in patient HM) because resection of temporal stem white matter potentially adds disruption of cholinergic inputs to temporal cortex to the obvious hippocampal damage. However, controversy persists because recent postmortem studies of patient HM have found little evidence of temporal stem interruption (Augustinack et al., 2014). In Alzheimer's disease, the cholinergic lesion can arise from coincident neurodegeneration within cholinergic nuclei rather than white matter disconnection. Human imaging studies of MCI and Alzheimer's disease demonstrate structural compromise of both the fornixillustrated by diffusion MRI (Metzler-Baddeley et al., 2012a; Douaud et al., 2013; Nowrangi et al., 2013)—and the cholinergic nuclei of the basal forebrain, illustrated by volumetric measurements (Grothe et al., 2012, 2013). Despite this, damage to the hippocampus-fornix is often viewed as the main driver of memory impairment. The current results show that both systems are potentially relevant to performance, at least in the early phase of disease represented by MCI. Rare case studies of direct injury to the basal forebrain-from vascular compression or rupture-in association with damage to frontal or medial temporal structures also support this concept (Parkin et al., 1996; Gao et al., 2013).

One potential substrate of the shift in association toward nonfornical tracts is a change in memory strategy, for example, a greater reliance on familiarity-based memory (Westerberg et al., 2006; Anderson et al., 2008). A key fact that links strategy with individual white matter pathways is the close anatomical concordance between specialized gray matter regions and the course of their projections. The overwhelming majority of fibers in the fornix reflect connections with the hippocampus and subiculum (Saunders and Aggleton, 2007), whereas those projections to and from parahippocampal cortices, implicated in other classes of memory, are more related to non-fornical routes, likely to include the PHC and uncinate fasciculus (Aggleton, 2012). However, the fact that DR correlated most strongly with free recall rather than with recognition measures may argue against a major role for familiarity in mediating the association between DR and performance. Another possibility is a role for meta-memory processes, such as recall confidence. The ventral parietal cortex has been implicated in confidence judgments, the PHC is well placed to mediate connectivity with medial temporal regions, and previous work showed an association between recall confidence and PHC microstructure (Metzler-Baddeley et al., 2012a). If individuals are more likely to express confidently recalled items but suppress items recalled with low confidence during free recall tasks and confidence judgments are supported by the PHC, then this might account for the relationship between DR calculated for left PHC and performance.

The present results also support one hypothesis (Parent and Baxter 2004) to explain why selective lesions of the cholinergic input to the hippocampus often fail to reproduce the effect of wider cholinergic lesions, on ostensibly hippocampal forms of memory (McMahan et al., 1997; for review, see Easton et al., 2012). If the cholinergic system promotes recruitment of non- hippocampal networks (Tang et al., 1997) and their associated strategies, then this process would presumably depend on cholinergic projections to cortical regions outside the hippocampus. More extensive lesions would, thereby, damage key mechanisms of compensation as well as primary mechanisms of hippocampal forms of memory. The idea of a shift in memory strategy can be interpreted within this framework: acetylcholine supports alternative non-hippocampal forms of memory that use connections in non-fornical tracts, thereby facilitating useful reconfiguration of memory processes in the context of fornix damage.

One limitation of the present approach is that the evaluation of the cholinergic system was restricted to volumetric measurements of gray matter. Although the regional effects were found to be specific for cholinergic basal forebrain regions, particularly the NBM, as determined by histological mapping (Teipel et al., 2005; Kilimann et al., 2014), these measures may not provide a comprehensive account of cholinergic function (Sarter and Bruno, 2002). Others have documented altered levels of cortical acetylcholinesterase using $\left[{ }^{11} \mathrm{C}\right] \mathrm{MP} 4 \mathrm{~A}$ and positron emission tomography in MCI (Haense et al., 2012), which could be combined with current methods to further test the hypothesis that acetylcholine facilitates reconfiguration of structure-function relationships.

The major implication of the positive relationship observed is that, although basal forebrain structures generally degenerate in $\mathrm{MCI}$, the individual degree of structural preservation appears to determine an individual's capacity for useful adaptation to pathology, through reconfiguration of white matter networks, which in turn helps to maintain performance. Promotion of synaptic plasticity in regions connected to the $\mathrm{PHC}$ is one plausible mechanism (Easton et al., 2012). Intriguingly, given the current results, one study has shown an association between structural connectivity profiles derived from diffusion imaging and exposure to cholinesterase inhibitors (Bozzali et al., 2013). However, this was a cross-sectional analysis based on historic exposure and so requires additional confirmation. Alternatively, cholinergic signaling might facilitate the use of redundant connectivity through intact, alternative connection pathways. Appreciation of the contribution of white matter structure to brain plasticity is increasing (Zatorre et al., 2012). A link with neurotransmitter systems has major implications for functional restoration.

\section{References}

Aggleton JP (2012) Multiple anatomical systems embedded within the primate medial temporal lobe: implications for hippocampal function. Neurosci Biobehav Rev 36:1579-1596. CrossRef Medline

Aggleton JP, Brown MW (2006) Interleaving brain systems for episodic and recognition memory. Trends Cogn Sci 10:455-463. CrossRef Medline

Aggleton JP, Friedman DP, Mishkin M (1987) A comparison between the connections of the amygdala and hippocampus with the basal forebrain in the macaque. Exp Brain Res 67:556-568. Medline

Aggleton JP, McMackin D, Carpenter K, Hornak J, Kapur N, Halpin S, Wiles CM, Kamel H, Brennan P, Carton S, Gaffan D (2000) Differential cognitive effects of colloid cysts in the third ventricle that spare or compromise the fornix. Brain 123:800-815. CrossRef Medline

Albert MS, DeKosky ST, Dickson D, Dubois B, Feldman HH, Fox NC, Gamst A, Holtzman DM, Jagust WJ, Petersen RC, Snyder PJ, Carrillo MC, Thies B, Phelps CH (2011) The diagnosis of mild cognitive impairment due to Alzheimer's disease: recommendations from the National Institute on Aging-Alzheimer's Association workgroups on diagnostic guidelines for Alzheimer's disease. Alzheimers Dement 7:270-279. CrossRef Medline

Anderson ND, Ebert PL, Jennings JM, Grady CL, Cabeza R, Graham SJ (2008) Recollection- and familiarity-based memory in healthy aging and amnestic mild cognitive impairment. Neuropsychology 22:177-187. CrossRef Medline

Ashburner J (2007) A fast diffeomorphic image registration algorithm. Neuroimage 38:95-113. CrossRef Medline 
Augustinack JC, van der Kouwe AJ, Salat DH, Benner T, Stevens AA, Annese J, Fischl B, Frosch MP, Corkin S (2014) H.M.'s contributions to neuroscience: a review and autopsy studies. Hippocampus 24:1267-1286. CrossRef Medline

Baddeley AD, Emslie H, Nimmo-Smith I (1994) Doors and people test. Bury St. Edmunds, UK: Thames Valley Test Company.

Berlot R, Metzler-Baddeley C, Jones DK, O'Sullivan MJ (2014) CSF contamination contributes to apparent microstructural alterations in mild cognitive impairment. Neuroimage 92:27-35. CrossRef Medline

Bozzali M, Parker GJ, Spanò B, Serra L, Giulietti G, Perri R, Magnani G, Marra C, G Vita M, Caltagirone C, Cercignani M (2013) Brain tissue modifications induced by cholinergic therapy in Alzheimer's disease. Hum Brain Mapp 34:3158-3167. CrossRef Medline

Browning PGF, Gaffan D, Croxson PL, Baxter MG (2010) Severe scene learning impairment, but intact recognition memory, after cholinergic depletion of inferotemporal cortex followed by fornix depletion. Cereb Cortex 20:282-293. CrossRef Medline

Croxson PL, Browning PGF, Gaffan D, Baxter MG (2012) Acetylcholine facilitates recovery of episodic memory after brain damage. J Neurosci 32:13787-13795. CrossRef Medline

Delis DC, Kaplan E, Kramer JH (2001) Delis-Kaplan Executive Function System (D-KEFS). Oxford, UK: Pearson Assessment.

D’Esposito M, Verfaellie M, Alexander MP, Katz DI (1995) Amnesia following traumatic bilateral fornix transection. Neurology 45:1546-1550. CrossRef Medline

Douaud G, Menke RAL, Gass A, Monsch AU, Rao A, Whitcher B, Zamboni G, Matthews PM, Sollberger M, Smith S (2013) Brain microstructure reveals early abnormalities more than two years prior to clinical progression from mild cognitive impairment to Alzheimer's disease. J Neurosci 33: 2147-2155. CrossRef Medline

Easton A, Douchamps V, Eacott M, Lever C (2012) A specific role for septohippocampal acetylcholine in memory? Neuropsychologia 50:31563168. CrossRef Medline

Gaffan D (2002) Against memory systems. Philos Trans R Soc Lond B Biol Sci 357:1111-1121. CrossRef Medline

Gaffan D, Gaffan EA (1991) Amnesia in man following transection of the fornix. A review. Brain 114:2611-2618. CrossRef Medline

Gao FQ, Pettersen JA, Bocti C, Nestor SM, Kiss A, Black SE (2013) Is encroachment of the carotid termination into the substantia innominata associated with its atrophy and cognition in Alzheimer's disease? Neurobiol Aging 34:1807-1814. CrossRef Medline

Grober E, Merling A, Heimlich T, Lipton RB (1997) Free and cued selective reminding and selective reminding in the elderly. J Clin Exp Neuropsychol 19:643-654. CrossRef Medline

Grothe M, Heinsen H, Teipel SJ (2012) Atrophy of the cholinergic Basal forebrain over the adult age range and in early stages of Alzheimer's disease. Biol Psychiatry 71:805-813. CrossRef Medline

Grothe M, Heinsen H, Teipel S (2013) Longitudinal measures of cholinergic forebrain atrophy in the transition from healthy aging to Alzheimer's disease. Neurobiol Aging 34:1210-1220. CrossRef Medline

Haense C, Kalbe E, Herholz K, Hohmann C, Neumaier B, Krais R, Heiss WD (2012) Cholinergic system function and cognition in mild cognitive impairment. Neurobiol Aging 33:867-877. CrossRef Medline

Horel JA (1978) The neuroanatomy of amnesia. A critique of the hippocampal memory hypothesis. Brain 101:403-445. CrossRef Medline

Jeurissen B, Leemans A, Jones DK, Tournier JD, Sijbers J (2011) Probabilistic fiber tracking using the residual bootstrap with constrained spherical deconvolution. Hum Brain Mapp 32:461-479. CrossRef Medline

Jones DK, Horsfield MA, Simmons A (1999) Optimal strategies for measuring diffusion in anisotropic systems by magnetic resonance imaging. Magn Reson Med 42:515-525. CrossRef Medline

Kilimann I, Grothe M, Heinsen H, Alho EJL, Grinberg L, Amaro E Jr, Dos Santos GAB, da Silva RE, Mitchell AJ, Frisoni GB, Bokde ALW, Fellgiebel A, Filippi M, Hampel H, Klöppel S, Teipel SJ (2014) Subregional basal forebrain atrophy in Alzheimer's disease: a multicenter study. J Alzheimers Dis 40:687-700. CrossRef Medline

Kitt CA, Mitchell SJ, DeLong MR, Wainer BH, Price DL (1987) Fiber pathways of basal forebrain cholinergic neurons in monkeys. Brain Res 406: 192-206. CrossRef Medline

Koliatsos VE, Martin LJ, Walker LC, Richardson RT, DeLong MR, Price DL (1988) Topographic, non-collateralized basal forebrain projections to the amygdala, hippocampus, and anterior cingulate cortex in the rhesus monkey. Brain Res 463:133-139. CrossRef Medline

Leemans A, Jones DK (2009) The B-matrix must be rotated when correcting for subject motion in DTI data. Magn Reson Med 61:1336-1349. CrossRef Medline

McMackin D, Cockburn J, Anslow P, Gaffan D (1995) Correlation of fornix damage with memory impairment in six cases of colloid cyst removal. Acta Neurochir 135:12-18. CrossRef Medline

McMahan RW, Sobel TJ, Baxter MG (1997) Selective immunolesions of hippocampal cholinergic input fail to impair spatial working memory. Hippocampus 7:130-136. CrossRef Medline

Mesulam MM (1995) Cholinergic pathways and the ascending reticular activating system of the human brain. Ann NY Acad Sci 757:169-179. CrossRef Medline

Mesulam MM, Mufson EJ, Levey AI, Wainer BH (1983) Cholinergic innervation of cortex by the basal forebrain: cytochemistry and cortical connections of the septal area, diagonal band nuclei, nucleus basalis (substantia innominata), and hypothalamus in the rhesus monkey. J Comp Neurol 214:170-197. CrossRef Medline

Metzler-Baddeley C, Jones DK, Belaroussi B, Aggleton JP, O’Sullivan MJ (2011) Frontotemporal connections in episodic memory and aging: a diffusion MRI tractography study. J Neurosci 31:13236-13245. CrossRef Medline

Metzler-Baddeley C, Hunt S, Jones DK, Leemans A, Aggleton JP, O’Sullivan MJ (2012a) Temporal association tracts and the breakdown of episodic memory in mild cognitive impairment. Neurology 79:2233-2240. CrossRef Medline

Metzler-Baddeley C, O’Sullivan MJ, Bells S, Pasternak O, Jones DK (2012b) How and how not to correct for CSF-contamination in diffusion MRI. Neuroimage 59:1394-1403. CrossRef Medline

Mioshi E, Dawson K, Mitchell J, Arnold R, Hodges JR (2006) The Addenbrooke's Cognitive Examination Revised (ACE-R): a brief cognitive test battery for dementia screening. Int J Geriatr Psychiatry 21:1078-1085. CrossRef Medline

Morris JC (1993) The Clinical Dementia Rating (CDR): current version and scoring rules. Neurology 43:2412-2414. CrossRef Medline

Muir JL, Page KJ, Sirinathsinghji DJ, Robbins TW, Everitt BJ (1993) Excitotoxic lesions of basal forebrain cholinergic neurons: effects on learning, memory and attention. Behav Brain Res 57:123-131. CrossRef Medline

Nelson HE, Willison J (1991) National Adult Reading Test (NART) test manual (2nd ed). Windsor, UK: NFER-Nelson.

Nichols T, Hayasaka S (2003) Controlling the familywise error rate in functional neuroimaging: a comparative review. Stat Methods Med Res 12: 419-446. CrossRef Medline

Nowrangi MA, Lyketsos CG, Leoutsakos JMS, Oishi K, Albert M, Mori S, Mielke MM (2013) Longitudinal, region-specific course of diffusion tensor imaging measures in mild cognitive impairment and Alzheimer's disease. Alzheimers Dement 9:519-528. CrossRef Medline

Parent MB, Baxter MG (2004) Septohippocampal acetylcholine: involved in but not necessary for learning and memory? Learn Mem 11:9-20. CrossRef Medline

Parkin AJ, Bindschaedler C, Harsent L, Metzler C (1996) Pathological false alarm rates following damage to the left frontal cortex. Brain Cogn 32:14-27. CrossRef Medline

Pasternak O, Sochen N, Gur Y, Intrator N, Assaf Y (2009) Free water elimination and mapping from diffusion MRI. Magn Reson Med 62:717-730. CrossRef Medline

Poletti CE, Creswell G (1977) Fornix system efferent projections in the squirrel monkey: an experimental degeneration study. J Comp Neurol 175:101-128. CrossRef Medline

Randolph C, Tierney MC, Mohr E, Chase TN (1998) The Repeatable Battery for the Assessment of Neuropsychological Status (RBANS): preliminary clinical validity. J Clin Exp Neuropsychol 20:310-319. CrossRef Medline

Rudebeck SR, Scholz J, Millington R, Rohenkohl G, Johansen-Berg H, Lee ACH (2009) Fornix microstructure correlates with recollection but not familiarity memory. J Neurosci 29:14987-14992. CrossRef Medline

Sarter M, Bruno JP (2002) The neglected constituent of the basal forebrain corticopetal projection system: GABAergic projections. Eur J Neurosci 15:1867-1873. CrossRef Medline

Saunders RC, Aggleton JP (2007) Origin and topography of fibers contrib- 
uting to the fornix in macaque monkeys. Hippocampus 17:396-411. CrossRef Medline

Sexton CE, Mackay CE, Lonie JA, Bastin ME, Terrière E, O'Carroll RE, Ebmeier KP (2010) MRI correlates of episodic memory in Alzheimer's disease, mild cognitive impairment, and healthy aging. Psychiatry Res 184:57-62. CrossRef Medline

Tang Y, Mishkin M, Aigner TG (1997) Effects of muscarinic blockade in perirhinal cortex during visual recognition. Proc Natl Acad Sci U S A 94:12667-12669. CrossRef Medline

Teipel SJ, Flatz WH, Heinsen H, Bokde AL, Schoenberg SO, Stöckel S, Dietrich O, Reiser MF, Möller HJ, Hampel H (2005) Measurement of basal forebrain atrophy in Alzheimer's disease using MRI. Brain 128:26262644. CrossRef Medline

Tournier JD, Calamante F, Connelly A (2007) Robust determination of the fibre orientation distribution in diffusion MRI: non-negativity constrained super-resolved spherical deconvolution. Neuroimage 35:14591472. CrossRef Medline

Tournier JD, Yeh CH, Calamante F, Cho KH, Connelly A, Lin CP (2008) Resolving crossing fibres using constrained spherical deconvolution: validation using diffusion-weighted imaging phantom data. Neuroimage 42:617-625. CrossRef Medline
Trenerry MR, Crosson B, DeBoe J, Leber WR (1989) Stroop Neuropsychological Screening Test. Odessa, FL: Psychological Assessment Resources.

Tsivilis D, Vann SD, Denby C, Roberts N, Mayes AR, Montaldi D, Aggleton JP (2008) A disproportionate role for the fornix and mammillary bodies in recall versus recognition memory. Nat Neurosci 11:834-842. CrossRef Medline

Vann SD, Tsivilis D, Denby CE Quamme JR, Yonelinas AP, Aggleton JP, Montaldi D, Mayes AR (2009) Impaired recollection but spared familiarity in patients with extended hippocampal system damage: convergence across three methods. Proc Natl Acad Sci U S A 106:5442-5447. CrossRef Medline

Wechsler D (1999) Wechsler Adult Intelligence Scale-3rd UK Edition (WAISIII UK). Oxford, UK: Psychological Corporation and Pearson Assessment.

Westerberg CE, Paller KA, Weintraub S, Mesulam MM, Holdstock JS, Mayes AR, Reber PJ (2006) When memory does not fail: familiarity-based recognition in mild cognitive impairment and Alzheimer's disease. Neuropsychology 20:193-205. CrossRef Medline

Zatorre RJ, Fields RD, Johansen-Berg H (2012) Plasticity in gray and white: neuroimaging changes in brain structure during learning. Nat Neurosci 15:528-536. CrossRef Medline 